JURNAL KETAHANAN NASIONAL

Vol. 24, No.1, April 2018, Hal 60-76

DOI:http://dx.doi.org/ 10.22146/jkn.30270

ISSN:0853-9340(Print), ISSN:2527-9688(Online)

Online sejak 28 Desember 2015 di :http://jurnal.ugm.ac.id/JKN

VOLUME 24

No. 1, April 2018

Halaman 60-76

\title{
Akses, Penggunaan Dan Faktor Penentu Pemanfaatan Teknologi Informasi Dan Komunikasi Pada Kawasan Pertanian Komersial Untuk Mendukung Ketahanan Pangan Di Perdesaan Yogyakarta
}

\author{
Subejo \\ Prodi Penyuluhan dan Komunikasi Pertanian, Fakultas Pertanian UGM \\ dan Prodi Penyuluhan dan Komunikasi Pembangunan SPS UGM \\ Email: Subejo@ugm.ac.id \\ Ratih Ineke Wati \\ Prodi Penyuluhan dan Komunikasi Pertanian, Fakultas Pertanian UGM \\ dan Prodi Penyuluhan dan Komunikasi Pembangunan SPS UGM \\ Email: ratihinekewati@gmail.com \\ Mesalia Kriska \\ Prodi Penyuluhan dan Komunikasi Pertanian, Fakultas Pertanian UGM \\ Email: mesaliakriska@yahoo.com \\ Najmu Tsaqib Akhda \\ Prodi Penyuluhan dan Komunikasi Pembangunan SPS UGM \\ Email:najm7779@gmail.com \\ Ade Intan Christian \\ Prodi Penyuluhan dan Komunikasi Pembangunan SPS UGM \\ Email:adeintan0@gmail.com \\ Ani Dwi Wimatsari \\ Prodi Penyuluhan dan Komunikasi Pembangunan SPS UGM \\ Email:anidwi94@gmail.com \\ Paksi Mei Penggalih \\ Prodi Penyuluhan dan Komunikasi Pembangunan SPS UGM \\ Email:paksimei@gmail.com
}

\begin{abstract}
Utilization of information and communication technologies (ICTS) had changed the diversity of agricultural extension and communication services which required alternatives for users of the services. Higher and better speed of information services was considerably recquired for supporting the sustainability of commercial farming business which in turn could facilitate the achievement of high status of food resilience. The goals of research were: (1). Describing access and function of ICTs for agricultural community, (2). Describing pattern on the usage of ICTs for supporting agricultural activities, (3). Analyzing the determinant factors on the usage of ICTs for supporting agricultural activities.

The research method used in the study was analytical descriptive with survey research technique. The sites of study were commercial farming areas in Yogyakarta namely Patuk Gunungkidul, Turi Sleman, Sanden Bantul and Panjatan Kulon Progo. Sample were selected by using simple random sampling method. Data had been collected by using structured questionnaire, observation and indepth interview. While data analysis had been done by using descriptive statistic and multiple regression.
\end{abstract}


Subejo, Ratih Ineke Wati, Mesalia Kriska, Najmu Tsaqib Akhda, Ade Intan Christian, Ani Dwi Wimatsari, Paksi Mei Penggalih -- Akses, Penggunaan dan Faktor Penentu Pemanfaatan Teknologi Informasi dan Komunikasi Pada Kawasan Pertanian Komersial untuk Mendukung Ketahanan Pangan di Perdesaan Yogyakarta

Study results showed that (1). Ownership of ICTs media in all of research sites was considerably high including conventional media and new media which both had high capability providing information and entertaninment, but the function on education was still considerably limited, (2). Utilization of ICTs for supporting agricultural activities was: conventional media (television and radio) for providing information on technical production, policy and marketing, while new media (handphone and smartphone) for providing information on technical production, policy, marketing and financial aspect, (3). Determinant factors on ownership of ICTs were age and social status, and (4). Determinant factors on the usage of ICTs for supporting agricultural activities were age and sex offarmers.

Keywords: Access, Determinant Factor, Technology of Information, Agriculture, Commercial, Food Resilience

\begin{abstract}
ABSTRAK
Pemanfaatan Teknologi Informasi dan Komunikasi (TIK) menyebabkan adanya perubahan keragaman (diversifikasi) layanan penyuluhan dan komunikasi pertanian yang memberi alternatif lebih baik bagi para pengguna layanan. Kecepatan layanan informasi sangat diperlukan untuk mendukung keberlanjutan pertanian komersial sehingga pada gilirannya dapat berkontribusi pada pencapaian ketahanan pangan yang tinggi. Tujuan penelitian adalah (1) Mengetahui akses dan fungsi TIK bagi masyarakat pertanian, (2) Mengetahui pola penggunaan TIK untuk pertanian oleh masyarakat pertanian dan (3) Mengetahui faktor-faktor yang mempengaruhi penggunaan TIK untuk mendukung kegiatan pertanian.

Metode penelitian yang digunakan adalah deskriptif analitik dengan teknik penelitian survey. Lokasi penelitian adalah kawasan pertanian komersial di Yogyakarta yang mencakup Patuk Gunungkidul, Turi Sleman, Sanden Bantul dan Panjatan Kulon Progo. Sampel dipilih dengan teknik simple random sampling. Data dikumpulkan dengan menggunakan kuesioner terstruktur, observasi dan wawancara mendalam. Analisis data dilakukan dengan menggunakan analisis statistik deskriptif dan dan regresi berganda.

Hasil studi menunjukkan bahwa (1). Kepemilikan media TIK di semua lokasi kajian cukup tinggi (media konvensional dan media baru) yang mampu melayani penyediaan informasi dan hiburan, namun fungsi edukasi masih sangat terbatas, (2). Penggunaan media TIK untuk mendukung kegiatan pertanian: media konvensional (televisi radio) untuk teknis produksi, kebijakan dan pemasaran, sedangkan media baru untuk untuk informasi teknis produksi, pemasaran, kebijakan dan pembiayaan, (3). Faktor penetu kepemilikan media TIK adalah umur dan status sosial, (4) Faktor penentu penggunaan TIK untuk mendukung aktivitas pertanian adalah umur dan jenis kelamin.
\end{abstract}

\title{
Kata Kunci: Akses, Faktor Pengaruh, Teknologi Informasi, Pertanian, Komersial, Ketahanan Pangan.
}

\section{PENGANTAR}

Pencapaian ketahanan pangan nasional sebagai salah satu tujuan utama pembangunan pertanian dan perdesaan di Indonesia menjadi isu yang sangat strategis dari waktu ke waktu. Desain kebijakan dan strategi ketahan pangan menjadi perhatian penting bagi pemerintah pusat maupun pemerintah daerah (Subejo, dkk, 2017). Salah satu prasyarat keberhasilan pencapaian ketahanan pangan adalah dukungan inovasi teknologi, ketepatan fasilitasi dan pertukaran informasi antar pemangku kepentingan yang terlibat dalam pembangunan pertanian. Efektivitas dan efisiensi proses penyebarluasan inovasi teknologi pertanian, ketepatan fasilitasi dan pertukaran informasi yang berimbang memerlukan dukungan penuh dari penyuluhan pertanian.

Dalam konteks pembangunan pertanian di Indoensia, Mulyandari dalam Elian dkk., (2014) menyatakan berbagai penelitian terkait dengan teknologi dan inovasi pertanian sudah cukup banyak dilaksanakan baik di dalam maupun luar negeri. Hasil penelitian pertanian pada dasarnya merupakan informasi penting terkait dengan teknik produksi dan pemasaran yang dirancang untuk dapat memperbaiki atau memecahkan masalah dalam bidang pertanian. Informasi tersebut bukan hanya sekedar konsumsi dan bahan acuan bagi 
para peneliti lain, namun juga diperuntukkan untuk para petani sebagai inovasi yang dapat diterapkan untuk meningkatkan produktivitas dan akhirnya dapat meningkatkan taraf hidup petani. Berbagai upaya telah dilakukan untuk mengghimpun dan mempublikasikan hasilhasil penelitian pertanian kepada masyarakat melalui berbagai media, namun demikian, informasi hasil penelitian pertanian tersebut belum dapat disebarluaskan secara efektif dan efisien kepada para petani sebagai sasaran utama pembangunan pertanian.

Akses pelaku utama pembangunan pertanian yaitu petani terhadap berbagai informasi dan inovasi pertanian menjadi isu yang sangat krusial dalam menentukan keberhasilan pembangunan pertanian dan pedesaan (Subejo, 2011). Keberhasilan pencapaian efektivitas diseminasi informasi dan inovasi pertanian melalui kebijakan dan program penyuluhan pertanian memiliki kaitan erat dengan kemampuan adaptasi terhadap dinamika perubahan global, pemanfaatan potensi-potensi nasional serta karakteristik sosial-ekonomi masyarakat.

Pendekatan dan praktek penyuluhan pertanian pada skala global maupun nasional mengalami terus mengalami perubahan yang dinamis. Perubahan pendekatan dan paradigma penyuluhan pertanian sebagaimana dicatat oleh Subejo (2011), digambarkan dalam satu-dua dasa warsa terakhir terdapat suatu perubahan paradigma dalam penyelenggaraan penyuluhan pertanian di negara-negara berkembang (termasuk di Indonesia) yang disebabkan oleh berbagai perubahan dan tuntutan global. Kecepatan dan ketepatan penyampaian informasi teknologi dan alternatif serta berbagai solusi efektif sangat perlu diperhatikan. Sejak satu-dua dasa warsa terakhir di banyak negara maju bahkan juga negara berkembang mulai memberikan perhatian yang besar bagi pemanfaatan Information and Communication Technologies (ICTs) untuk penyelenggaraan penyuluhan pertanian dan pedesaan. Di Indonesia, aplikasi ICTs untuk mendukung program pembangunan pertanian dikenal dengan istilah Teknologi Informasi dan Komunikasi (TIK). Sharma (2006) memberikan istilah pemanfaatan ICTs/TIK untuk penyuluhan pertanian dengan sebutan Cyber Extension (penggunaan jaringan on-line, computer dan digital interactive multimedia untuk diseminasi teknologi pertanian).

Peneliti TIK untuk pembangunan pertanian Yadav (2015) menyatakan bahwa media merupakan powerful medium untuk mempromosikan berbagai sektor pembangunan di pedesaan. Hasil penelitian studi kasus menunjukkan 90\% masyarakat di Nanded (pedesaan India) mendengarkan radio dalam kesehariannya. Beberapa media yang memiliki pengaruh pada pembangunan pedesaan mencakup TV, Radio, Internet dan smartphone. Meskipun media elektronik secara umum telah digunaan oleh masyarakat desa, namun media elektronik belum memainkan peran yang efektif untuk diseminasi informasi pertanian. Beberapa penyebab rendahnya penggunaan media elektronik untuk pertanian adalah kurang cocoknya inovasi yang disampaikan dengan keadaan lokal, kurang cocoknya bahasa dalam penyampaian, biaya media elektronik yang cukup mahal, ahli di bidang pertanian tidak mau menggunakan media elektronik dan kurangnya dukungan pembiayaan pengembangan media elektronik untuk penyuluhan pertanian. Jika hambatan tersebut dapat diatasi, peluang dan prospek pemanfaatan TIK untuk mendukung keberhasilan pembangunan pertanian akan semakin baik pada masa-masa mendatang. 
Subejo, Ratih Ineke Wati, Mesalia Kriska, Najmu Tsaqib Akhda, Ade Intan Christian, Ani Dwi Wimatsari, Paksi Mei Penggalih -- Akses, Penggunaan dan Faktor Penentu Pemanfaatan Teknologi Informasi dan Komunikasi Pada Kawasan Pertanian Komersial untuk Mendukung Ketahanan Pangan di Perdesaan Yogyakarta

Teknologi Informasi dan Komunikasi atau secara global dikenal sebagai Information and Communication Technologies sudah merambah ke perdesaan dan menyentuh berbagai aspek kehidupan, bahkan sudah mulai dimanfaatkan untuk mendukung berbagai aktivitas pertanian. Hasil studi pendahuluan oleh Subejo dkk., (2016) tentang pemanfaatan teknologi informasi dan komunikasi di kalangan petani telah menemukan pada kawasan pertanian komersial hortikultura (cabai dan semangka) di Kabupaten Kulon Progo, media TV dan radio masih dominan digunakan oleh petani, sedangkan handphone dan smartphonel internet sudah mulai digunakan untuk mengakses informasi pertanian. Sedangkan di kawasan pertanian pangan di Sleman dan kawasan agro forestry di Gunungkidul, penggunaan media elektronik yang dominan adalah media TV dan radio sementara handphone dan internet belum banyak digunakan untuk mendukung aktivitas pertanian.

Berdasar hasil kajian sebelumnya, kajian lanjutan terkait pemenfaatan TIK di kawasan pertanian komersial perlu dikaji lebih mendalam. Oleh karena itu, akses, fungsi, pola penggunaan, dan faktorfaktor yang mempengaruhi pemanfaatan TIK pada kawasan pertanian komersial di Yogyakarta sangat menarik untuk diteliti secara lebih komprehensif. Kawasan pertanian komersial di Yogyakarta antara lain mencakup kawasan pengembangan kakao di Kecamatan Patuk Kabupaten Gunungkidul, kawasan pengembangan salak pondoh di Kecamatan Turi Kabupaten Sleman, kawasan pengembangan hortikultura (cabai merah) di Kecamatan Panjatan Kabupaten Kulon Progo dan kawasan pengembangan hortikultura (bawang merah) di Kecamatan Sanden Kabupaten Bantul.

Secara rinci tujuan penelitian ini adalah (1). Mengetahui akses dan fungsi TIK bagi petani di kawasan pertanian komersial di perdesaan Yogyakarta, (2). Mengetahui pola penggunaan TIK untuk petani di kawasan pertanian komersial di perdesaan Yogyakarta dan (3). Mengetahui faktor-faktor yang mempengaruhi penggunaan TIK untuk pertanian oleh petani di kawasan pertanian komersial di perdesaan Yogyakarta.

Metode dasar yang digunakan dalam penelitian adalah metode deskriptif analitik dengan pendekatan campuran (mixed method) yang merupakan gabungan pendekatan kuantitatif dan kualitatif. Sedangkan teknik penelitian yang digunakan adalah survey. Populasi dalam penelitian ini adalah petani kakao di Patuk Gunung Kidul, petani salak pondoh di Turi Sleman, petani bawang merah di Sanden Bantul, dan petani hortikultura di Panjatan Kulon Progo. Pemilihan sampel dilakukan secara acak sederhana di masingmasing lokasi. Data dikumpulkan dengan menggunakan kuesioner terstruktur, observasi lapangan dan indepth interview terhadap informan kunci. Analisis data dilakukan dengan menggunakan analisis statistik deskriptif dan dan regresi berganda.

\section{PEMBAHASAN}

\section{Kondisi Umum Wilayah Penelitian}

Penelitian dilakukan pada 4 lokasi di Daerah Istimewa Yogyakarta dimana pada masing-masing lokasi kajian memiliki komoditas agro yang dikembangkan secara komersial. Komoditas unggulan tersebut mewakili kelompok hortikultura (sayuran dan buah) serta perkebunan. Karakteristik dasar wilayah penelitian tersaji dalam tabel 1 . 


\section{Karakteristik Sosial Ekonomi Petani}

Karakteristik sosial ekonomi yang dikaji mencakup: jenis kelamin, umur, pendidikan, status sosial, jenis pekerjaan serta komoditas yang dikembangkan. Secara garis besar karakteristik umum sosial-ekonomi petani pada kawasan pertanian komersial diuraikan pada bagian selanjutnya.

Sebagian besar petani di semua lokasi kajian berjenis kelamin laki-laki kecuali di Gunung Kidul. Kepala keluarga (laki-laki) di Gunungkidul umumnya konsentrasi pada usaha pertanian pada musim tanam dan panen sedangkan pada waktu yang lain umumnya bekerja pada sektor yang menghasilkan cash income seperti buruh bangunan, tukang kayu, penjual makanan, dll.

Berdasarkan kelompok umur, sebagian besar petani di lokasi kajian termasuk dalam kategori umur muda (20-55 tahun). Proporsi petani dengan umur tua (lebih dari 55 tahun) yang cukup besar ada di Sleman. Petani Sleman merupakan petani komoditas salak yang umumnya sudah cukup tua dan menekuni usaha salak sejak turun temurun dan mandegnya regenerasi petani menjadi salah satu isu penting.

Ditinjau dari aspek pendidikan petani, kondisi pendidikan yang terbaik di Kulon Progo dimana 63,33\% petani lulus SLTA berikutnya Bantul (56,67\%), Gunungkidul $(30,00 \%)$ dan Sleman (19,23\%). Petani Kulon
Progo dan Bantul merupakan petani muda yang enerjik dengan pendidikan cukup baik yang menekuni pertanian komersial di lahan pesisir sejak tahun 1990an. Sedangkan ditinjau dari status sosial, sebagian besar petani responden merupakan anggota kelompok atau organsiasi sosial.

Berdasarkan jenis usaha yang dikelola, petani yang sepenuhnya menekuni pertanian komersial dengan proporsi yang besar adalah petani di Sleman $(69,23 \%)$ disusul petani Kulon Progo (36,37\%). Usahatani salak merupakan usaha yang dominan di Kecamatan Turi dan petani memiliki ketergantungan yang tinggi, sedangkan di Panjatan Kulon Progo sejalan dengan meningkatnya prospek ekonomi sub-sektor hortikultura menyebabkan semakin banyak petani muda yang fokus pada pengembangan komoditas cabai dan semangka.

Komoditas pertanian yang dominan di Bantul dan Kulon Progo merupakan tanaman hortikultura semusim yang merupakan cash crops, di Sleman merupakan hortikultura yang bersifat tahunan (salak pondoh); sedangkan di Gunungkidul yang merupakan daerah pegunungan, komoditas pertanian yang dominan dikembangkan merupakan tanaman tahunan (kakao dan kayu-kayuan).

Secara rinci, karakteristik sosial-ekonomi petani pola pertanian komersial di lokasi empat kajian disajikan pada tabel 2, 3 dan 4.

Tabel 1

Karakteristik Dasar Wilayah Penelitian

\begin{tabular}{|c|c|c|c|c|}
\hline Kabupaten & Kecamatan/ Desa & Kondisi Topografi & $\begin{array}{l}\text { Komoditas yang } \\
\text { Dominan }\end{array}$ & Tipologi Komoditas \\
\hline Gunungkidul & Patuk/ Nglanggeran & Berbukit & Kakao & Tanaman tahunan \\
\hline Sleman & Turi/ Wonokerto & Dataran tinggi & Salak pondoh & Tanaman tahunan \\
\hline Bantul & Sanden/ Gedangsari & $\begin{array}{l}\text { Dataran rendah yang } \\
\text { landai dan berpasir }\end{array}$ & Bawang merah & Tanaman semusim \\
\hline Kulon Progo & $\begin{array}{l}\text { Panjatan/Bugel dan } \\
\text { Garongan }\end{array}$ & Dataran rendah & Cabai, Semangka & Tanaman semusim \\
\hline
\end{tabular}


Subejo, Ratih Ineke Wati, Mesalia Kriska, Najmu Tsaqib Akhda, Ade Intan Christian, Ani Dwi Wimatsari, Paksi Mei Penggalih -- Akses, Penggunaan dan Faktor Penentu Pemanfaatan Teknologi Informasi dan Komunikasi Pada Kawasan Pertanian Komersial untuk Mendukung Ketahanan Pangan di Perdesaan Yogyakarta

Kepemilikan TIK oleh Keluarga Petani

Rerata kepemilikan media TIK di semua lokasi kajian cukup tinggi, selain media konvensional televisi dimana pada masingmasing rumah tangga memiliki lebih dari 1 unit; kepemilikan media baru (new media) seperti handphone dan smartphone juga sangat tinggi dengan rerata diatas $120 \%$. Kepemilikan media baru oleh Petani di Kulon Progo dan Gunungkidul melebihi 150\%.
Rerata kepemilikan media elektronik disajikan pada tabel 5 .

\section{Pemanfaatan TIK Untuk Mendukung Usaha Bidang Pertanian}

Pemanfaatan media elektronik dalam bidang pertanian menunjukkan hasil dan kecenderungan yang berbeda pada masingmasing kabupaten. Secara keseluruhan dari total enam media yang ada, hanya empat

Tabel 2

Sebaran Petani Menurut Karakteristik Responden (\%)

\begin{tabular}{lcrrrrrrrrrrrr}
\hline \multirow{2}{*}{ Lokasi } & \multicolumn{2}{c}{ Jenis Kelamin } & \multicolumn{3}{c}{ Umur (tahun) } & \multicolumn{3}{c}{ Tingkat Pendidikan } & \multicolumn{3}{c}{ Status Sosial } \\
\cline { 2 - 11 } & Laki-laki & Perempuan & $20-35$ & $36-55$ & $56-70$ & SD & SMP & SMA & PT & $\begin{array}{c}\text { Ang- } \\
\text { gota }\end{array}$ & Pengurus \\
\hline Bantul (n=30) & 76.67 & 23.33 & 6.67 & 76.67 & 16.67 & 20.00 & 20.00 & 56.67 & 3.33 & 86.67 & 13.33 \\
Sleman (n=26) & 73.08 & 26.92 & 3.85 & 50.00 & 46.15 & 46.15 & 34.62 & 19.23 & 0.00 & 69.23 & 30.77 \\
Kulon Progo (n=30) & 100.00 & 0.00 & 16.67 & 66.67 & 16.67 & 10.00 & 26.67 & 63.33 & 0.00 & 76.67 & 23.33 \\
$\begin{array}{l}\text { Gunungkidul } \\
(\mathrm{n}=30)\end{array}$ & 36.67 & 63.33 & 16.67 & 63.33 & 20.00 & 46.67 & 23.33 & 30.00 & 0.00 & 76.67 & 23.33 \\
\hline
\end{tabular}

Sumber: Analisis Data Primer, 2017

Tabel 3

Sebaran Petani Menurut Jenis Pekerjaan

\begin{tabular}{lccc}
\hline Lokasi Penelitian & \multicolumn{3}{c}{ Jenis Pekerjaan (\%) } \\
\cline { 2 - 4 } & Petani Komersial & Petani Komersial dan Usahatani Lainnya & Pekerjaan Sampingan Non-Petani \\
\hline Bantul (n=30) & 20,00 & 60,00 & 26,67 \\
Sleman (n=26) & 69,23 & 23,08 & 15,38 \\
Kulon Progo & 36,67 & 60,00 & 30,00 \\
$(\mathrm{n}=30)$ & 16,67 & 83,33 & 40,00 \\
$\begin{array}{l}\text { Gunungkidul } \\
(\mathrm{n}=30)\end{array}$ & & & 400 \\
\hline
\end{tabular}

Sumber: Analisis Data Primer, 2017

Tabel 4.

Komoditas Pertanian Yang Diusahakan Petani

\begin{tabular}{ll}
\hline Lokasi & Kenis Komoditas Pertanian yang Diusahakan \\
\hline Bantul & Cabai, bawang merah, kacang tanah, jagung, ketela, kangkung, padi, tomat, terong, pare \\
Sleman & Salak (Pondoh, Gading, Madu), padi \\
Kulon Progo & $\begin{array}{l}\text { Cabai, semangka, terong, padi, sawi, kangkung, kacang panjang, bawang merah, mentimun, } \\
\text { sosin/caisan, gambas/oyong, kelapa }\end{array}$ \\
Kunungkidul & $\begin{array}{l}\text { Kakao, jati, karet, mahoni, durian, alpukat, kelengkeng, cengkeh, rambutan, ketela, pisang, } \\
\text { mentimun, jagung, padi, cabai, kacang tanah }\end{array}$ \\
\hline
\end{tabular}

Sumber: Analisis Data Primer, 2017 
Tabel 5

Kepemilikan TIK Oleh Rumah Tangga Petani Di Lokasi Kajian

\begin{tabular}{|c|c|c|c|c|c|c|c|c|c|c|c|c|}
\hline \multirow[b]{2}{*}{ Lokasi } & \multicolumn{2}{|c|}{ Televisi } & \multicolumn{2}{|c|}{ Radio } & \multicolumn{2}{|c|}{ Handphone } & \multicolumn{2}{|c|}{ Smartphone } & \multicolumn{2}{|c|}{ Laptop } & \multicolumn{2}{|c|}{$\mathrm{VCD} / \mathrm{DVD}$} \\
\hline & $\begin{array}{c}\text { Jum- } \\
\text { lah } \\
(\%)\end{array}$ & $\begin{array}{c}\text { Rerata } \\
\text { Lama } \\
\text { Kepemi- } \\
\text { likan } \\
\text { (tahun) }\end{array}$ & $\begin{array}{c}\text { Jum- } \\
\text { lah } \\
(\%)\end{array}$ & $\begin{array}{c}\text { Rerata } \\
\text { Lama } \\
\text { Kepemi- } \\
\text { likan } \\
\text { (tahun) }\end{array}$ & $\begin{array}{c}\text { Jumlah } \\
(\%)\end{array}$ & $\begin{array}{c}\text { Rerata } \\
\text { Lama } \\
\text { Kepe- } \\
\text { milikan } \\
\text { (tahun) }\end{array}$ & $\begin{array}{c}\text { Jum- } \\
\text { lah } \\
(\%)\end{array}$ & $\begin{array}{c}\text { Rerata } \\
\text { Lama } \\
\text { Kepemi- } \\
\text { likan } \\
\text { (tahun) }\end{array}$ & $\begin{array}{c}\text { Jumlah } \\
(\%)\end{array}$ & $\begin{array}{c}\text { Rerata } \\
\text { Lama } \\
\text { Kepe- } \\
\text { milikan } \\
\text { (tahun) }\end{array}$ & $\begin{array}{c}\text { Jum- } \\
\text { lah } \\
(\%)\end{array}$ & $\begin{array}{c}\text { Rerata } \\
\text { Lama } \\
\text { Kepemi- } \\
\text { likan }\end{array}$ \\
\hline Gunung- & & & & & & & & & & & & \\
\hline $\begin{array}{l}\text { kidul } \\
(\mathrm{n}=30)\end{array}$ & 123,3 & 14,2 & 107,7 & 11,25 & 152,6 & 5,96 & 182,4 & 2,5 & 133,3 & 0,5 & 100 & 4,7 \\
\hline $\begin{array}{l}\text { Sleman } \\
(\mathrm{n}=26)\end{array}$ & 129,2 & 14,0 & 100 & 15,2 & 147,1 & 8,5 & 127,2 & 1,8 & 100 & 0,9 & 100 & 2,5 \\
\hline $\begin{array}{l}\text { Bantul } \\
(\mathrm{n}=30)\end{array}$ & 100 & 14,5 & 100 & 12,8 & 111,1 & 5,5 & 135,7 & 1,8 & 114,3 & 1,7 & 100 & 2,9 \\
\hline $\begin{array}{l}\text { K u } 1 \text { o n } \\
\text { Progo } \\
(\mathrm{n}=25)\end{array}$ & 113,8 & 10,2 & 112,5 & 8,8 & 124 & 6 & 163,2 & 1,5 & 120 & 0,5 & 100 & 1,9 \\
\hline
\end{tabular}

Sumber: Analisis Data Primer, 2017

media yang mampu menyediakan informasi di bidang pertanian. Media tersebut yaitu televisi, radio, handphone, dan smartphone.

Terkait dengan pemanfatan TIK untuk mendukung pertanian, secara garis besar adalah sebagai berikut: (1). Petani komersial di Gunungkidul sering dan sangat sering menggunakan televisi untuk informasi tentang teknis produksi dan kebijakan; radio digunakan untuk informasi pemasaran, handphone digunakan untuk informasi pemasaran; smartphone untuk informasi teknis produksi dan kebijakan, (2). Petani komersial di Kulon Progo sering dan sangat sering menggunakan televisi untuk informasi tentang teknis produksi dan kebijakan; radio digunakan untuk cerita sukses; handphone digunakan untuk informasi pemasaran; smartphone untuk informasi teknis produksi dan kebijakan, (3). Petani komersial di Bantul sering dan sangat sering menggunakan televisi untuk informasi tentang teknis produksi, pemasaran dan kebijakan; radio digunakan untuk cerita sukses; handphone digunakan untuk informasi teknis produksi, pemasaran, kebijakan dan pembiayaan; smartphone untuk informasi teknis produksi, pemasaran, kebijakan, cerita sukses dan human interest, (4). Petani komersial di Kulon Progo sering dan sangat sering menggunakan televisi untuk informasi tentang teknis produksi, pemasaran dan kebijakan; radio digunakan untuk informasi pemasaran; handphone digunakan untuk informasi teknis produksi dan pemasaran; smartphone untuk informasi teknis produksi dan infromasi pemasaran.

Secara rinci fungsi dan pemanfaatan TIK dalam mendukung aktivitas pertanian di 4 lokasi kajian disajikan pada tabel 6, 7, 8 dan 9.

\section{Faktor Penentu Dalam Penggunaan TIK}

Akses para petani di pedesaan terhadap teknologi informasi dan komunikasi dapat direpresentasikan dengan jumlah kepemilikan media TIK yang menggambarkan kapasitas, fleksibilitas dan alternatif anggota masyarakat dalam memanfaatkan dan mengakses berbagai infromasi melalui TIK yang dimiliki. Hasil analisis regresi berganda pada faktor-faktor 
Subejo, Ratih Ineke Wati, Mesalia Kriska, Najmu Tsaqib Akhda, Ade Intan Christian, Ani Dwi Wimatsari, Paksi

Mei Penggalih -- Akses, Penggunaan dan Faktor Penentu Pemanfaatan Teknologi Informasi dan Komunikasi

Pada Kawasan Pertanian Komersial untuk Mendukung Ketahanan Pangan di Perdesaan Yogyakarta

Tabel 6

Fungsi TIK Bidang Pertanian Di Kabupaten Gunungkidul

\begin{tabular}{|c|c|c|c|c|c|c|}
\hline Jenis TIK & Fungsi TIK & $\mathrm{TP}(\%)$ & $\mathrm{J}(\%)$ & KK $(\%)$ & $\mathrm{S}(\%)$ & SS (\%) \\
\hline \multirow{6}{*}{$\begin{array}{l}\text { Televisi } \\
(n=24)\end{array}$} & Teknis Produksi & 4,17 & 25,00 & 45,83 & 25,00 & 0,00 \\
\hline & Pemasaran & 29,17 & 25,00 & 33,33 & 12,50 & 0,00 \\
\hline & Kebijakan & 41,67 & 12,50 & 16,67 & 25,00 & 4,17 \\
\hline & Cerita Sukses & 25,00 & 25,00 & 29,17 & 20,83 & 0,00 \\
\hline & Human Interest & 33,33 & 16,67 & 25,00 & 20,83 & 4,17 \\
\hline & Pembiayaan & 54,17 & 12,50 & 25,00 & 8,33 & 0,00 \\
\hline \multirow{6}{*}{$\begin{array}{l}\text { Radio } \\
(n=16)\end{array}$} & Teknis Produksi & 31,25 & 25,00 & 31,25 & 12,50 & 0,00 \\
\hline & Pemasaran & 56,25 & 12,50 & 18,75 & 12,50 & 0,00 \\
\hline & Kebijakan & 56,25 & 25,00 & 12,50 & 6,25 & 0,00 \\
\hline & Cerita Sukses & 50,00 & 12,50 & 12,50 & 25,00 & 0,00 \\
\hline & Human Interest & 50,00 & 18,75 & 12,50 & 18,75 & 0,00 \\
\hline & Pembiayaan & 68,75 & 12,50 & 18,75 & 0,00 & 0,00 \\
\hline \multirow{6}{*}{$\begin{array}{l}\text { Handphone } \\
\qquad(\mathrm{n}=18)\end{array}$} & Teknis Produksi & 44,44 & 16,67 & 5,56 & 16,67 & 16,67 \\
\hline & Pemasaran & 44,44 & 5,56 & 5,56 & 27,78 & 16,67 \\
\hline & Kebijakan & 55,56 & 16,67 & 0,00 & 22,22 & 5,56 \\
\hline & Cerita Sukses & 55,56 & 16,67 & 5,56 & 22,22 & 0,00 \\
\hline & Human Interest & 61,11 & 27,78 & 5,56 & 5,56 & 0,00 \\
\hline & Pembiayaan & 83,33 & 5,56 & 0,00 & 11,11 & 0,00 \\
\hline \multirow{6}{*}{$\begin{array}{l}\text { Smartphone } \\
\qquad(\mathrm{n}=11)\end{array}$} & Teknis Produksi & 54,55 & 9,09 & 9,09 & 27,27 & 0,00 \\
\hline & Pemasaran & 72,73 & 0,00 & 9,09 & 18,18 & 0,00 \\
\hline & Kebijakan & 54,55 & 9,09 & 9,09 & 27,27 & 0,00 \\
\hline & Cerita Sukses & 63,64 & 18,18 & 0,00 & 18,18 & 0,00 \\
\hline & Human Interest & 72,73 & 0,00 & 9,09 & 18,18 & 0,00 \\
\hline & Pembiayaan & 81,82 & 9,09 & 0,00 & 9,09 & 0,00 \\
\hline \multirow{6}{*}{$\begin{array}{c}\text { Laptop/PC } \\
\qquad(\mathrm{n}=3)\end{array}$} & Teknis Produksi & 66,67 & 33,33 & 0,00 & 0,00 & 0,00 \\
\hline & Pemasaran & 66,67 & 33,33 & 0,00 & 0,00 & 0,00 \\
\hline & Kebijakan & 66,67 & 33,33 & 0,00 & 0,00 & 0,00 \\
\hline & Cerita Sukses & 66,67 & 33,33 & 0,00 & 0,00 & 0,00 \\
\hline & Human Interest & 66,67 & 33,33 & 0,00 & 0,00 & 0,00 \\
\hline & Pembiayaan & 66,67 & 33,33 & 0,00 & 0,00 & 0,00 \\
\hline \multirow{6}{*}{$\begin{array}{l}\text { DVD } \\
(n=5)\end{array}$} & Teknis Produksi & 100,00 & 0,00 & 0,00 & 0,00 & 0,00 \\
\hline & Pemasaran & 100,00 & 0,00 & 0,00 & 0,00 & 0,00 \\
\hline & Kebijakan & 100,00 & 0,00 & 0,00 & 0,00 & 0,00 \\
\hline & Cerita Sukses & 100,00 & 0,00 & 0,00 & 0,00 & 0,00 \\
\hline & Human Interest & 100,00 & 0,00 & 0,00 & 0,00 & 0,00 \\
\hline & Pembiayaan & 100,00 & 0,00 & 0,00 & 0,00 & 0,00 \\
\hline
\end{tabular}

Sumber: Analisis data primer (2017)

Keterangan: $\mathrm{TP}=$ Tidak Pernah, $\mathrm{J}=\mathrm{Jarang}, \mathrm{KK}=$ Kadang-Kadang, $\mathrm{S}=$ Sering dan $\mathrm{SS}=$ Sangat Sering 
Tabel 7

Fungsi TIK Bidang Pertanian Di Kabupaten Sleman

\begin{tabular}{|c|c|c|c|c|c|c|}
\hline Jenis TIK & Fungsi TIK & $\mathrm{TP}(\%)$ & $\mathrm{J}(\%)$ & KK $(\%)$ & $\mathrm{S}(\%)$ & SS (\%) \\
\hline \multirow{6}{*}{$\begin{array}{l}\text { Televisi } \\
(n=24)\end{array}$} & Teknis Produksi & 4,17 & 25,00 & 45,83 & 25,00 & 0,00 \\
\hline & Pemasaran & 29,17 & 25,00 & 33,33 & 12,50 & 0,00 \\
\hline & Kebijakan & 41,67 & 12,50 & 16,67 & 25,00 & 4,17 \\
\hline & Cerita Sukses & 25,00 & 25,00 & 29,17 & 20,83 & 0,00 \\
\hline & Human Interest & 33,33 & 16,67 & 25,00 & 20,83 & 4,17 \\
\hline & Pembiayaan & 54,17 & 12,50 & 25,00 & 8,33 & 0,00 \\
\hline \multirow{6}{*}{$\begin{array}{l}\text { Radio } \\
(n=16)\end{array}$} & Teknis Produksi & 31,25 & 25,00 & 31,25 & 12,50 & 0,00 \\
\hline & Pemasaran & 56,25 & 12,50 & 18,75 & 12,50 & 0,00 \\
\hline & Kebijakan & 56,25 & 25,00 & 12,50 & 6,25 & 0,00 \\
\hline & Cerita Sukses & 50,00 & 12,50 & 12,50 & 25,00 & 0,00 \\
\hline & Human Interest & 50,00 & 18,75 & 12,50 & 18,75 & 0,00 \\
\hline & Pembiayaan & 68,75 & 12,50 & 18,75 & 0,00 & 0,00 \\
\hline \multirow{6}{*}{$\begin{array}{l}\text { Handphone } \\
\qquad(\mathrm{n}=18)\end{array}$} & Teknis Produksi & 44,44 & 16,67 & 5,56 & 16,67 & 16,67 \\
\hline & Pemasaran & 44,44 & 5,56 & 5,56 & 27,78 & 16,67 \\
\hline & Kebijakan & 55,56 & 16,67 & 0,00 & 22,22 & 5,56 \\
\hline & Cerita Sukses & 55,56 & 16,67 & 5,56 & 22,22 & 0,00 \\
\hline & Human Interest & 61,11 & 27,78 & 5,56 & 5,56 & 0,00 \\
\hline & Pembiayaan & 83,33 & 5,56 & 0,00 & 11,11 & 0,00 \\
\hline \multirow{6}{*}{$\begin{array}{l}\text { Smartphone } \\
\qquad(\mathrm{n}=11)\end{array}$} & Teknis Produksi & 54,55 & 9,09 & 9,09 & 27,27 & 0,00 \\
\hline & Pemasaran & 72,73 & 0,00 & 9,09 & 18,18 & 0,00 \\
\hline & Kebijakan & 54,55 & 9,09 & 9,09 & 27,27 & 0,00 \\
\hline & Cerita Sukses & 63,64 & 18,18 & 0,00 & 18,18 & 0,00 \\
\hline & Human Interest & 72,73 & 0,00 & 9,09 & 18,18 & 0,00 \\
\hline & Pembiayaan & 81,82 & 9,09 & 0,00 & 9,09 & 0,00 \\
\hline \multirow{6}{*}{$\begin{array}{l}\text { Laptop/PC } \\
\qquad(\mathrm{n}=3)\end{array}$} & Teknis Produksi & 66,67 & 33,33 & 0,00 & 0,00 & 0,00 \\
\hline & Pemasaran & 66,67 & 33,33 & 0,00 & 0,00 & 0,00 \\
\hline & Kebijakan & 66,67 & 33,33 & 0,00 & 0,00 & 0,00 \\
\hline & Cerita Sukses & 66,67 & 33,33 & 0,00 & 0,00 & 0,00 \\
\hline & Human Interest & 66,67 & 33,33 & 0,00 & 0,00 & 0,00 \\
\hline & Pembiayaan & 66,67 & 33,33 & 0,00 & 0,00 & 0,00 \\
\hline \multirow{6}{*}{$\begin{array}{l}\text { DVD } \\
(n=5)\end{array}$} & Teknis Produksi & 100,00 & 0,00 & 0,00 & 0,00 & 0,00 \\
\hline & Pemasaran & 100,00 & 0,00 & 0,00 & 0,00 & 0,00 \\
\hline & Kebijakan & 100,00 & 0,00 & 0,00 & 0,00 & 0,00 \\
\hline & Cerita Sukses & 100,00 & 0,00 & 0,00 & 0,00 & 0,00 \\
\hline & Human Interest & 100,00 & 0,00 & 0,00 & 0,00 & 0,00 \\
\hline & Pembiayaan & 100,00 & 0,00 & 0,00 & 0,00 & 0,00 \\
\hline
\end{tabular}

Sumber: Analisis data primer (2017)

Keterangan: $\mathrm{TP}=$ Tidak Pernah, $\mathrm{J}=$ Jarang, $\mathrm{KK}=$ Kadang-Kadang, $\mathrm{S}=$ Sering dan $\mathrm{SS}=$ Sangat Sering 
Subejo, Ratih Ineke Wati, Mesalia Kriska, Najmu Tsaqib Akhda, Ade Intan Christian, Ani Dwi Wimatsari, Paksi

Mei Penggalih -- Akses, Penggunaan dan Faktor Penentu Pemanfaatan Teknologi Informasi dan Komunikasi

Pada Kawasan Pertanian Komersial untuk Mendukung Ketahanan Pangan di Perdesaan Yogyakarta

Tabel 8

Fungsi TIK Bidang Pertanian Di Kabupaten Bantul

\begin{tabular}{|c|c|c|c|c|c|c|}
\hline Jenis TIK & Fungsi TIK & ТP (\%) & $\mathrm{J}(\%)$ & KK (\%) & S (\%) & SS (\%) \\
\hline \multirow{6}{*}{$\begin{array}{l}\text { Televisi } \\
(\mathrm{n}=29)\end{array}$} & Teknis Produksi & 10,34 & 24,14 & 34,48 & 27,59 & 3,45 \\
\hline & Pemasaran & 13,79 & 31,03 & 17,24 & 31,03 & 6,90 \\
\hline & Kebijakan & 24,14 & 24,14 & 20,69 & 24,14 & 6,90 \\
\hline & Cerita Sukses & 13,79 & 27,59 & 31,03 & 27,59 & 0,00 \\
\hline & Human Interest & 24,14 & 24,14 & 34,48 & 17,24 & 0,00 \\
\hline & Pembiayaan & 37,93 & 31,03 & 17,24 & 13,79 & 0,00 \\
\hline \multirow{6}{*}{$\begin{array}{l}\text { Radio } \\
(\mathrm{n}=22)\end{array}$} & Teknis Produksi & 27,27 & 27,27 & 9,09 & 31,82 & 4,55 \\
\hline & Pemasaran & 27,27 & 36,36 & 4,55 & 27,27 & 4,55 \\
\hline & Kebijakan & 45,45 & 27,27 & 9,09 & 13,64 & 4,55 \\
\hline & Cerita Sukses & 45,45 & 36,36 & 13,64 & 0,00 & 4,55 \\
\hline & Human Interest & 36,36 & 45,45 & 18,18 & 0,00 & 0,00 \\
\hline & Pembiayaan & 45,45 & 40,91 & 4,55 & 9,09 & 0,00 \\
\hline \multirow{6}{*}{$\begin{array}{l}\text { Handphone } \\
\quad(\mathrm{n}=18)\end{array}$} & Teknis Produksi & 33,33 & 5,56 & 11,11 & 33,33 & 16,67 \\
\hline & Pemasaran & 22,22 & 22,22 & 11,11 & 22,22 & 22,22 \\
\hline & Kebijakan & 38,89 & 22,22 & 11,11 & 22,22 & 5,56 \\
\hline & Cerita Sukses & 44,44 & 16,67 & 16,67 & 22,22 & 0,00 \\
\hline & Human Interest & 44,44 & 16,67 & 22,22 & 16,67 & 0,00 \\
\hline & Pembiayaan & 44,44 & 16,67 & 5,56 & 22,22 & 11,11 \\
\hline \multirow{6}{*}{$\begin{array}{l}\text { Smartphone } \\
\quad(\mathrm{n}=12)\end{array}$} & Teknis Produksi & 33,33 & 16,67 & 8,33 & 41,67 & 0,00 \\
\hline & Pemasaran & 25,00 & 16,67 & 8,33 & 50,00 & 0,00 \\
\hline & Kebijakan & 41,67 & 25,00 & 8,33 & 25,00 & 0,00 \\
\hline & Cerita Sukses & 41,67 & 25,00 & 8,33 & 25,00 & 0,00 \\
\hline & Human Interest & 33,33 & 25,00 & 16,67 & 25,00 & 0,00 \\
\hline & Pembiayaan & 41,67 & 33,33 & 8,33 & 16,67 & 0,00 \\
\hline \multirow{6}{*}{$\begin{array}{l}\text { Laptop/PC } \\
\qquad(\mathrm{n}=6)\end{array}$} & Teknis Produksi & 66,67 & 0,00 & 16,67 & 16,67 & 0,00 \\
\hline & Pemasaran & 66,67 & 0,00 & 16,67 & 16,67 & 0,00 \\
\hline & Kebijakan & 66,67 & 0,00 & 16,67 & 16,67 & 0,00 \\
\hline & Cerita Sukses & 66,67 & 0,00 & 16,67 & 16,67 & 0,00 \\
\hline & Human Interest & 66,67 & 0,00 & 16,67 & 16,67 & 0,00 \\
\hline & Pembiayaan & 83,33 & 0,00 & 0,00 & 16,67 & 0,00 \\
\hline \multirow{6}{*}{$\begin{array}{c}\text { DVD } \\
(\mathrm{n}=11)\end{array}$} & Teknis Produksi & 100,00 & 0,00 & 0,00 & 0,00 & 0,00 \\
\hline & Pemasaran & 100,00 & 0,00 & 0,00 & 0,00 & 0,00 \\
\hline & Kebijakan & 100,00 & 0,00 & 0,00 & 0,00 & 0,00 \\
\hline & Cerita Sukses & 100,00 & 0,00 & 0,00 & 0,00 & 0,00 \\
\hline & Human Interest & 100,00 & 0,00 & 0,00 & 0,00 & 0,00 \\
\hline & Pembiayaan & 100,00 & 0,00 & 0,00 & 0,00 & 0,00 \\
\hline
\end{tabular}

Sumber: Analisis Data Primer, 2017

Keterangan: $\mathrm{TP}=$ Tidak Pernah, J=Jarang, $\mathrm{KK}=$ Kadang-Kadang, $\mathrm{S}=$ Sering dan $\mathrm{SS}=$ Sangat Sering 
Tabel 9

Fungsi TIK Bidang Pertanian Di Kabupaten Kulon Progo

\begin{tabular}{|c|c|c|c|c|c|c|}
\hline Jenis TIK & Fungsi TIK & $\mathrm{TP}(\%)$ & $\mathrm{J}(\%)$ & KK $(\%)$ & $\mathrm{S}(\%)$ & SS $(\%)$ \\
\hline \multirow{6}{*}{$\begin{array}{l}\text { Televisi } \\
(n=29)\end{array}$} & Teknis Produksi & 6,90 & 34,48 & 27,59 & 27,59 & 3,45 \\
\hline & Pemasaran & 17,24 & 24,14 & 31,03 & 27,59 & 0,00 \\
\hline & Kebijakan & 24,14 & 27,59 & 17,24 & 27,59 & 3,45 \\
\hline & Cerita Sukses & 31,03 & 31,03 & 20,69 & 17,24 & 0,00 \\
\hline & Human Interest & 31,03 & 27,59 & 27,59 & 10,34 & 3,45 \\
\hline & Pembiayaan & 51,72 & 20,69 & 13,79 & 13,79 & 0,00 \\
\hline \multirow{6}{*}{$\begin{array}{l}\text { Radio } \\
(n=17)\end{array}$} & Teknis Produksi & 29,41 & 47,06 & 11,76 & 5,88 & 5,88 \\
\hline & Pemasaran & 52,94 & 29,41 & 5,88 & 11,76 & 0,00 \\
\hline & Kebijakan & 47,06 & 41,18 & 11,76 & 0,00 & 0,00 \\
\hline & Cerita Sukses & 47,06 & 52,94 & 0,00 & 0,00 & 0,00 \\
\hline & Human Interest & 47,06 & 52,94 & 0,00 & 0,00 & 0,00 \\
\hline & Pembiayaan & 58,82 & 35,29 & 0,00 & 5,88 & 0,00 \\
\hline \multirow{6}{*}{$\begin{array}{l}\text { Handphone } \\
\qquad(\mathrm{n}=25)\end{array}$} & Teknis Produksi & 40,00 & 28,00 & 8,00 & 16,00 & 8,00 \\
\hline & Pemasaran & 32,00 & 16,00 & 0,00 & 40,00 & 12,00 \\
\hline & Kebijakan & 40,00 & 44,00 & 12,00 & 4,00 & 0,00 \\
\hline & Cerita Sukses & 52,00 & 36,00 & 8,00 & 4,00 & 0,00 \\
\hline & Human Interest & 56,00 & 32,00 & 8,00 & 4,00 & 0,00 \\
\hline & Pembiayaan & 48,00 & 32,00 & 8,00 & 12,00 & 0,00 \\
\hline \multirow{6}{*}{$\begin{array}{l}\text { Smartphone } \\
\quad(n=20)\end{array}$} & Teknis Produksi & 45,00 & 15,00 & 5,00 & 20,00 & 15,00 \\
\hline & Pemasaran & 45,00 & 15,00 & 0,00 & 15,00 & 25,00 \\
\hline & Kebijakan & 60,00 & 10,00 & 15,00 & 10,00 & 5,00 \\
\hline & Cerita Sukses & 55,00 & 15,00 & 15,00 & 15,00 & 0,00 \\
\hline & Human Interest & 60,00 & 10,00 & 20,00 & 10,00 & 0,00 \\
\hline & Pembiayaan & 50,00 & 20,00 & 10,00 & 15,00 & 5,00 \\
\hline \multirow{6}{*}{$\begin{array}{l}\text { Laptop/PC } \\
\qquad(\mathrm{n}=8)\end{array}$} & Teknis Produksi & 87,50 & 0,00 & 0,00 & 12,50 & 0,00 \\
\hline & Pemasaran & 100,00 & 0,00 & 0,00 & 0,00 & 0,00 \\
\hline & Kebijakan & 100,00 & 0,00 & 0,00 & 0,00 & 0,00 \\
\hline & Cerita Sukses & 100,00 & 0,00 & 0,00 & 0,00 & 0,00 \\
\hline & Human Interest & 100,00 & 0,00 & 0,00 & 0,00 & 0,00 \\
\hline & Pembiayaan & 100,00 & 0,00 & 0,00 & 0,00 & 0,00 \\
\hline \multirow{6}{*}{$\begin{array}{l}\text { DVD } \\
(n=10)\end{array}$} & Teknis Produksi & 90,00 & 0,00 & 10,00 & 0,00 & 0,00 \\
\hline & Pemasaran & 100,00 & 0,00 & 0,00 & 0,00 & 0,00 \\
\hline & Kebijakan & 90,00 & 10,00 & 0,00 & 0,00 & 0,00 \\
\hline & Cerita Sukses & 100,00 & 0,00 & 0,00 & 0,00 & 0,00 \\
\hline & Human Interest & 100,00 & 0,00 & 0,00 & 0,00 & 0,00 \\
\hline & Pembiayaan & 100,00 & 0,00 & 0,00 & 0,00 & 0,00 \\
\hline
\end{tabular}

Sumber: Analisis Data Primer, 2017

Keterangan: $\mathrm{TP}=$ Tidak Pernah, $\mathrm{J}=\mathrm{Jarang}, \mathrm{KK}=$ Kadang-Kadang, $\mathrm{S}=$ Sering dan $\mathrm{SS}=$ Sangat Sering 
Subejo, Ratih Ineke Wati, Mesalia Kriska, Najmu Tsaqib Akhda, Ade Intan Christian, Ani Dwi Wimatsari, Paksi Mei Penggalih -- Akses, Penggunaan dan Faktor Penentu Pemanfaatan Teknologi Informasi dan Komunikasi Pada Kawasan Pertanian Komersial untuk Mendukung Ketahanan Pangan di Perdesaan Yogyakarta

yang mempengaruhi pemanfaatan TIK untuk mendukung berbagai kepentingan yang menunjang kebutuhan hidup sehari-hari dan faktor penetu pada penggunaan media untuk mengakses berbagai informasi pertanian secara disajikan pada tabel 10 .

Berdasarkan tabel 10 pada aspek kepemilikan media TIK diketahui nilai signifikansi variabel umur dan status sosial lebih kecil daripada taraf signifikansi $\alpha=$ 0,1 dan memiliki nilai koefisien positif $(+)$ sehingga variabel umur dan status sosial berpengaruh signifikan positif terhadap kepemilikan media yang dapat dimanfaatkan oleh para petani untuk mengakses berbagai informasi untuk mendukung kehidupan seharihari. Hasil analisis menunjukkan semakin tua umur petani maka jumlah media yang dimiliki oleh petani semakin banyak dan para petani yang memiliki status sebagai pengurus dalam kelompok sosial-ekonomi maka media yang dimiliki oleh petani semakin banyak.

Petani yang relatif tua karena akses dan kapasitasnya pada media baru (new media) relatif terbatas maka tidak memiliki ketergantungan pada media tertentu yang spesifik (handphone, smartphone dan internet) sehingga untuk dapat menjamin berbagai kebutuhannya akan informasi untuk mendukung aktivitas seharihari akan memanfaatkan TIK yang lebih beragam (lebih banyak jenis media), sedangkan generasi baru petani (generasi Y) cenderung memiliki akses dan kapasitas yang tinggi dalam memanfatakan media baru sehngga akan lebih fokus pada pemanfaatan media baru tertentu dalam memperoleh berbagai informasi untuk mendukung aktivitas sehari-hari (lebih sedikit jenis medianya).

Status sosial sebagai pengurus institusi sosial-ekonomi dalam masyarakat nampaknya juga membutuhkan kelengkapan akses dan berbagai variasi informasi yang dapat diperoleh dari berbagai jenis TIK sehingga mampu melayani kebutuhan informasi diri sendiri dan mendukung pemenuhan kebutuhan para anggota institusi yang dikelolanya. Petani yang memiliki status sebagai anggota institusi nampaknya cukup memanfaakan jenis TIK tertentu untuk memenuhi kebutuhan informasi bagi dirinya sendiri. Oleh karenanya, petani yang memiliki status sosial sebagai pengurus institusi sosial-ekonomi cenderung memiliki jumlah TIK yang lebih banyak yang dapat dipakai untuk mengakses berbagai informasi pertanian dibanding dengan petani yang yang hanya sebagai anggota institusi.

Tabel 10

Faktor Penentu Yang Mempengaruhi Kepemilikan Media TIK dan Penggunaan Media TIK Untuk Pertanian

\begin{tabular}{lcc}
\hline Faktor Penentu & Kepemilikan Media TIK & Media TIK untuk Pertanian \\
\hline Umur & $0,02^{*}$ & $0,009^{*}$ \\
Jenis kelamin & $0,242^{\text {ns }}$ & $0,014^{*}$ \\
Pendidikan & $0,477^{\text {ns }}$ & $0,900^{\text {ns }}$ \\
Status sosial & $0,005^{*}$ & $0,354^{\text {ns }}$ \\
Jenis pekerjaan & $0,969^{\text {ns }}$ & $0,394^{\text {ns }}$ \\
Luas lahan & $0,885^{\text {ns }}$ & $0,772^{\text {ns }}$ \\
Lama bertani & $0,139^{\text {ns }}$ & $0,518^{\text {ns }}$ \\
Pendapatan & $0,133^{\text {ns }}$ & $0,409^{\text {ns }}$ \\
\hline
\end{tabular}

Sumber : Analisis Data Primer, 2017

Keterangan : tingkat kesalahan $\alpha=10 \%$

$\mathrm{Ns}=$ Tidak ada pengaruh antara variabel independen terhadap variabel dependen

*= Terdapat pengaruh antara variabel independen terhadap variabel dependen 
Pada aspek pemanfaatan TIK untuk pertanian seperti tersaji pada tabel 10 , menunjukkan nilai signifikansi variabel umur dan jenis kelamin lebih kecil daripada taraf signifikansi $\alpha=0,1$ dan memiliki nilai koefisien positif $(+)$ sehingga variabel umur dan jenis kelamin berpengaruh signifikan positif terhadap jumlah media yang digunakan petani untuk menunjang berbagai informasi dan kegiatan bidang pertanian. Hasil analisis menunjukkan semakin tua petani akan cenderung memiliki jumlah media yang lebih banyak, dan petani laki-laki cenderung memiliki jumlah TIK yang lebih banyak yang dimanfaatkan untuk mendukung kegiatan dan infromasi bidang pertanian.

Hasil kajian Arnania-Kepuladze (2010) menunjukkan jenis kelamin menentukan keagresifan dalam pencapaian tugas. Perbedaan jenis kelamin akan mempengaruhi motivasikerja dalam melaksanakan tugas dan tanggungjawab. Oleh karena itu hasil penelitian ini dimana jenis kelamin mempengaruhi penggunaan media untuk pertanian sesuai dengan temuan Arnania-Kepuladze. Petani yang relatif tua karena akses dan kapasitasnya pada media baru tertentu (new media) relatif terbatas maka tidak memiliki ketergantungan pada media ternetentu yang sepesifik (handphone, smartphone dan internet) sehingga untuk dapat menjamin berbagai kebutuhannya akan informasi untuk mendukung aktivitas bidang pertanian akan memanfaatkan TIK yang lebih beragam (lebih banyak jenis media), sedangkan generasi baru petani (generasi Y) cenderung memiliki akses dan kapasitas yang tinggi dalam memanfatakan media baru sehingga akan lebih fokus pada pemanfaatan media baru tertentu dalam memperoleh berbagai informasi untuk mendukung aktivitas di bidang pertanian (lebih sedikit jenis medianya).
Meskipun peran perempuan dalam aktivitas bidang pertanian di daerah pedesaan semakin menguat sebagaimana dalam kajian Subejo (2012) disebut sebagai fenomena agriculture feminization, namun nampaknya untuk usaha-usaha pertanian komersial di kawasan pertanian Yogyakarta, peran laki-laki dalam kegiatan-kegiatan poduksi pertanian komersial masih cukup dominan dan strategis. Keterlibatan laki-laki yang masih cukup dominan dalam berbagai aktivitas produksi dan pasca panen nampaknya juga memerlukan dukungan berbagai informasi yang dapat diperoleh melalui TIK sehingga kepemilikan TIK oleh petani laki-laki lebih tinggi dibanding kepemilikan TIK oleh perempuan yang dipakai untuk mendukung berbagai kebutuhan informasi dan inovasi bidang pertanian.

Petani di empat lokasi kajian memiliki karakteristik usaha pertanian yang mirip yaitu komoditas pertanian komersial, namun terdapat keragaman pada kondisi sosial ekonomi masyarakat dan kondisi geografis pada masing-masing lokasi. Hasil analisis faktorfaktor yang mempengaruhi pemanfaatan TIK pada masing-masing wilayah pengembangan komoditas pertanian komersial disajikan pada tabel 11.

Meskipun analisis terpisah berbasis kewilayahan pengembangan komoditas pertanian komersial memiliki keterbatasan dalam jumlah responden petani yang relatif kecil untuk masing-masing lokasi kajian, namun dalam batas tertentu dapat dikomparasikan determinan faktor penggunaan TIK untuk mendukung aktivitas bisnis pertanian komersial di masing-masing lokasi kajian. Pada kawasan pertanian komersial Kulon Progo, tidak ada determinan faktor yang spesifik yang menentukan penggunaan 
Subejo, Ratih Ineke Wati, Mesalia Kriska, Najmu Tsaqib Akhda, Ade Intan Christian, Ani Dwi Wimatsari, Paksi Mei Penggalih -- Akses, Penggunaan dan Faktor Penentu Pemanfaatan Teknologi Informasi dan Komunikasi Pada Kawasan Pertanian Komersial untuk Mendukung Ketahanan Pangan di Perdesaan Yogyakarta

Tabel 11

Faktor Penentu Pemanfaatan TIK Berbasis Wilayah Pengembangan Komoditas Pertanian Komersial Di Yogyakarta

\begin{tabular}{|c|c|c|c|c|c|}
\hline \multirow{2}{*}{ No. } & \multirow{2}{*}{ Variabel } & \multicolumn{4}{|c|}{ Wilayah Pengembangan Komoditas Pertanian Komersial } \\
\hline & & Kulon Progo & Bantul & Sleman & Gunungkidul \\
\hline 1. & Umur & $-0,006^{\mathrm{ns}}$ & $-0,014^{\mathrm{ns}}$ & $-0,003^{\text {ns }}$ & $-0,095^{*}$ \\
\hline 2. & Jenis Kelamin & - & $0,855^{*}$ & $-0,058^{\mathrm{ns}}$ & $0,967^{\mathrm{ns}}$ \\
\hline 3. & Pendidikan & $0,033^{\mathrm{ns}}$ & $-0,098^{\mathrm{ns}}$ & $0,135^{\mathrm{ns}}$ & $-0,114^{\mathrm{ns}}$ \\
\hline 4. & Status & $-0,520^{\mathrm{ns}}$ & $0,753^{\mathrm{ns}}$ & $1,420^{*}$ & $0,379^{\text {ns }}$ \\
\hline 5. & Pekerjaan & $0,451^{\mathrm{ns}}$ & $-0,126^{\mathrm{ns}}$ & $-0,319^{\text {ns }}$ & $1,251^{\mathrm{ns}}$ \\
\hline 6. & Luas Lahan & $0,090^{\mathrm{ns}}$ & $0,056^{\mathrm{ns}}$ & $2,230^{\mathrm{ns}}$ & $0,122^{\mathrm{ns}}$ \\
\hline 7. & Lama Bertani & $-0,027^{\mathrm{ns}}$ & $-0,027^{\mathrm{ns}}$ & $0,016^{\mathrm{ns}}$ & $0,043^{\text {ns }}$ \\
\hline 8. & Pendapatan & $0,042^{\text {ns }}$ & $0,004^{\mathrm{ns}}$ & $-0,508^{\mathrm{ns}}$ & $-0,272^{\text {ns }}$ \\
\hline & Konstanta & $2,464^{\mathrm{ns}}$ & $3,965^{*}$ & $0,599^{\mathrm{ns}}$ & $6,008 *$ \\
\hline
\end{tabular}

Keterangan :

Sumber : Analisis Data Primer, 2017

Tingkat kesalahan $\alpha=10 \%$

Ns = Tidak ada pengaruh antara variabel independen terhadap variabel dependen

*=Terdapat pengaruh antara variabel independen terhadap variabel dependen

TIK untuk pertanian, semua petani telah memiliki TIK yang diteliti (televisi, radio, handphone, smartphone, laptop, $\mathrm{VCD} /$ DVD). Faktor penentu penggunaan TIK pada kawasan pertanian komersial di Bantul guna mendukung kegiatan pertanian adalah jenis kelamin. Pada kawasan pertanian komersial di Sleman, faktor penentu penggunaan TIK untuk pertanian adalah status sosial petani. Sedangkan di kawasan pertanian komersial Gunung Kidul, faktor penentu penggunaan TIK untuk pertanian adalah umur.

Semua rumah tangga petani di Kulon Progo memiliki semua jenis TIK yang diteliti (televisi, radio, handphone, smartphone, laptop, VCD/DVD) sebagaimana secara rinci disajikan pada tabel 5 pada bagian sebelumnya. Bahkan rerata kepemilikan televisi, radio, handphone, smartphone, laptop pada rumah tangga petani melebihi 100 persen yang berarti dalam satu rumah tangga memiliki lebih dari satu media tersebut. Khusuanya untuk media baru yaitu handphone dan smartphone, proporsi kepemilikannya lebih dari 120 persen. Kondisi kepemilikan media TIK yang sangat tinggi ini nampaknya juga menunjukkan media TIK telah menjadi kebutuhan, kebiasaan dan gaya hidup masyarakat untuk mengakses berbagai kebutuhan informasi baik untuk kepentingan informasi umum maupun yang terkait dengan informasi terkait bidang pertanian sehingga tidak ada faktor penentu yang spesifik.

Keterlibatan laki-laki yang masih cukup dominan dalam berbagai aktivitas produksi dan pasca panen pada usaha komoditas pertanian komersial bawang merah dan komoditas agro lainnya di Pesisir Selatan Kabupaten Bantul nampaknya juga memerlukan dukungan berbagai informasi yang dapat diperoleh memalui TIK sehingga kepemilikan TIK oleh petani laki-laki lebih tinggi dibanding kepemilikan TIK oleh perempuan yang dipakai untuk mendukung berbagai kebutuhan informasi dan inovasi bidang pertanian.

Dalam batas tertentu, status sosial warga masyarakat terkait dengan kapasitas dan kecukupan informasi yang dibutuhkan. Status sosial sebagai pengurus dalam institusi sosial- 
ekonomi dalam masyarakat pada kawasan pertanian komersial dengan komoditas utama salak pondi di Kabupaten Sleman nampaknya juga membutuhkan kelengkapan akses dan berbagai variasi informasi yang dapat diperoleh dari berbagai jenis TIK sehingga mampu melayani kebutuhan informasi diri sendiri dan mendukung pemenuhan kebutuhan para anggota institusi yang dikelolanya, sedangkan anggota institusi nampaknya cukup memanfaatkan jenis TIK tertentu untuk memenuhi kebutuhan informasi diri sendiri terkait dengan pengambangan komoditas salak pondoh. Oleh karenanya, petani yang memiliki status sosial sebagai pengurus institusi sosial-ekonomi cenderung memiliki jumlah TIK yang lebih banyak dibanding dengan petani yang memiliki status sebagai anggota institusi. Dalam konteks pengembangan komoditas salak pondoh, sejak beberapa tahun terakhir sudah mulai dilakukan perintisan ekspor salak ke beberapa negara tujuan dan juga dilakukan pengembangan industri olahan berbasis salak (keripik, manisan, dodol, kopi biji salak, dll), oleh karenanya keragaman informasi terkait pengembangan produk salak dan olahannya sangat diperlukan sehingga peran pengurus kelompok menjadi strategis untuk mempu menyediakan kebutuhan informasi terkait.

Hasil analisis faktor penentu penggunaan TIK untuk pertanian di Gunungkidul dapat dimaknai semakin tua umur maka pemanfaatan TIK untuk pertanian semakin menurun. Petani berumur tua nampaknya lebih mengandalkan media komunikasi konvensional seperti tatap muka dengan petugas dan belajar dari sesama petani dalam mengakses informasi terkait pengembangan kakao di Gunung Kidul, sedangkan petani muda sudah mulai memanfaatkan berbagai media TIK untuk mengakses informasi dan inovasi baru tentang pengembangan komoditas kakao.

\section{SIMPULAN}

Berdasarkan pada hasil analisis dan pembahasan, beberapa simpulan penting yang bisa ditarik dalam studi ini adalah sebagai berikut.

Pertama, kepemilikan media TIK di semua lokasi kajian cukup tinggi, selain media konvensional televisi dimana pada masingmasing rumah tangga memiliki lebih dari 1 unit, kepemilikan media baru (handphone dan smartphone) juga sangat tinggi rerata di atas 120\% bahkan untuk petani di Kulon Progo dan Gunungkidul kepemilikan media baru melebihi 150\%. Media TIK konvensional (televisi dan radio) dipandang memainkan peran penting dalam penyediaan informasi dan hiburan bagi masyarakat tani di pedesaan, selain itu media baru (handphone dan smartphone) juga dipandang semakin penting untuk melayani kebutuhan informasi dan fungsi penyediaan hiburan. Fungsi edukasi baik pada media konvensional maupun media baru dipandang masih sangat terbatas.

Kedua, penggunaan media TIK untuk mendukung kegiatan pertanian: (1). Petani komersial di Gunungkidul sering dan sangat sering menggunakan televisi untuk informasi tentang teknis produksi dan kebijakan; radio digunakan untuk informasi pemasaran, handphone digunakan untuk informasi pemasaran; smartphone untuk informasi teknis produksi dan kebijakan, (2). Petani komersial di Kulon Progo sering dan sangat sering menggunakan televisi untuk informasi tentang teknis produksi dan kebijakan; radio digunakan untuk cerita sukses; handphone digunakan untuk informasi pemasaran; smartphone untuk informasi teknis produksi dan kebijakan, 
Subejo, Ratih Ineke Wati, Mesalia Kriska, Najmu Tsaqib Akhda, Ade Intan Christian, Ani Dwi Wimatsari, Paksi Mei Penggalih -- Akses, Penggunaan dan Faktor Penentu Pemanfaatan Teknologi Informasi dan Komunikasi Pada Kawasan Pertanian Komersial untuk Mendukung Ketahanan Pangan di Perdesaan Yogyakarta

(3). Petani komersial di Bantul sering dan sangat sering menggunakan televisi untuk informasi tentang teknis produksi, pemasaran dan kebijakan; radio digunakan untuk cerita sukses; handphone digunakan untuk informasi teknis produksi, pemasaran, kebijakan dan pembiayaan; smartphone untuk informasi teknis produksi, pemasaran, kebijakan, cerita sukses dan human interest, (4). Petani komersial di Kulon Progo sering dan sangat sering menggunakan televisi untuk informasi tentang teknis produksi, pemasaran dan kebijakan; radio digunakan untuk informasi pemasaran; handphone digunakan untuk informasi teknis produksi dan pemasaran; smartphone untuk informasi teknis produksi dan informasi pemasaran.

Ketiga, variabel umur dan status sosial berpengaruh signifikan positif terhadap kepemilikan media yang dapat dimanfaatkan oleh para petani untuk mengakses berbagai informasi untuk mendukung kehidupan seharihari. Hasil analisis menunjukkan semakin tua umur petani maka jumlah media yang dimiliki oleh petani semakin banyak dan para petani yang memiliki status sosial sebagai pengurus dalam kelompok sosial-ekonomi maka media yang dimiliki oleh petani semakin banyak untuk mendukung akses informasi yang bersifat umum. Sedangkan variabel umur dan jenis kelamin berpengaruh signifikan positif terhadap jumlah media yang digunakan petani untuk menunjang berbagai informasi dan kegiatan bidang pertanian. Hasil analisis menunjukkan semakin tua petani akan cenderung memiliki jumlah media yang lebih banyak, dan petani lakilaki cenderung memiliki jumlah TIK yang lebih banyak yang dimanfaatkan untuk mendukung berbagai kegiatan dan informasi bidang pertanian pada kawasan pertanian komersial.

Berdasarkan pada simpulan, beberapa rekomendasi yang dapat diusulkan menjadi solusi penting dalam pemanfaatan TIK untuk mendukung pengembangan komoditas pertanian pada kawasan pertanian komersial Yogyakarta adalah sebagai beruikut.

Pertama, pemanfaatan media konvensional (televisi dan radio) dan media baru (handphone dan smartphone) pada masa mendatang akan semakin strategis untuk memenuhi kebutuhan informasi dan hiburan. Fungsi edukasi perlu menjadi perhatian pengembangan media konvensional dan media baru pada masa mendatang.

Kedua, penggunaan media TIK untuk kegiatan pertanian pada kawasan pertanian komersial perlu semakin ditingkatkan variasi isinya sehingga lebih komprehensif yang mencakup semua aspek yaitu teknis produksi, pemasaran, kebijakan, cerita sukses, human interest dan pembiayaan pertanian.

Ketiga, petani muda dan petani senior dapat saling melengkapi dan bertukar informasi yang diperoleh sesuai dengan karakteristiknya masing-masing dimana petani senior cenderung mengakses banyak media sedangkan petani muda cenderung fokus dalam mengakses media baru yang menyajikan informasi lebih rinci dengan kecepatan tinggi.

Keempat, petani yang memiliki status sosial sebagai pengurus institusi sosial ekonomi yang cendrung aktif dalam memanfatan berbagai TIK juga perlu berbagi informsi (information sharing) dengan seluruh anggotanya sehingga secara terintegrasi akan memberikan kemanfaatan untuk seluruh warga masyarakat baik dalam kehidupan sehari-hari maupun usaha pertanian.

Kelima, perbaikan infrastruktur telekomunikasi dan peningkatan kualitas layanan (termasuk variasi dan muatan content) informasi yang disajikan dalam berbagai TIK yang diakses oleh petani juga menjadi isu 
strategis yang perlu menjadi perhatian para aktor yang terlibat.

\section{DAFTAR PUSTAKA}

Arnania-Kepuladze, T. 2010. Gender Stereotypes and Gender Feature of Job Motivation: Differences or Similarity?. Problem and Perspective in Management 8(2): 84-93 https://businessperspectives. org/journals? task $=$ callelement\&format $=$ raw\&item_id $=3227 \&$ element $=e 46 c d b 75$ ca7e-4c69-97ee-741acaab6046\&method $=$ download\&args $[0]=0$

Elian, N., Lubis, D. P., Rangkuti, P.A. 2014. Penggunaan Internet dan Pemanfaatan Informasi Pertanian oleh Penyuluh Pertanian di Kabupaten Bogor Wilayah Barat. Jurnal Komunikasi Pembangunan, Juli 2014, Vol.12, No.2 (104-109). Institut Pertanian Bogor, Jawa Barat. http:// journal.ipb.ac.id/index.php/jurnalkmp/ article/viewFile/8666/pdf

Sharma, P.V. 2006. Cyber Extension: Information and Communication Technology (ICT) Applications for Agricultural Extension ServicesChallenges. Opportunities, Issues and Strategies in "Enchangement of Extension System in Agriculture". Sharma, PV (ed). APO. Tokyo. http:// www. apo-tokyo.org/00e-books/ AG-16_EnhanceExtSystem/AG-16_ EnhanceExtSystem.pdf

Subejo.2011. Babak Baru Penyuluhan Pertanian dan Pedesaan. Jurnal Ilmu-Ilmu Pertanian, Juli 2011, Vol. 7, Nomor 1 (61-
70). Sekolah Tinggi Penyuluhan Pertanian Yogyakarta-Kementan, Yogyakarta. http://stppyogyakarta.ac.id/wp-content/ uploads/2012/04/IIP_0701_2011_Subejo. $p d f$

Subejo. 2012. Agriculture Feminization. The Jakarta Post. Paper Edition 2012. http://www. thejakartapost. com/news/2012/09/05/a-new-trendagriculture-feminization.html

Subejo; Untari, Dyah Woro; Ineke Wati, Rati dan Mewasdinta, Gagar. 2016. Akses dan Pemanfaatan TIK untuk Pertanian di Yogyakarta, Laporan Hibah Penelitian Fakultas Pertanian UGM Tahun Anggaran 2016 (tidak dipublikasikan)

Subejo, Fidiastry A., Aryudian C., Suadi, Awluddin L., Marfai M.A. 2017. Food Insecurity as a Basis for Drafting a. Strategic Food Sovereignty Plan: A Case Study of the Kutai Kartanegara District, Indonesia. Quaestiones Geographicae. 36(4):141-158, Bogucki Wydawnictwo Naukowe, PoznańPoland. https://www.degruyter.com/ downloadpdf/j/quageo.2017.36.issue-4/ quageo-2017-0042/quageo-2017-0042. $x m l$

Yadav, K. B. 2015. A Critical Study and Analysis of Electronic Media and Rural Development. International Journal of English Language, Literature, and Humanities. Vol. III (IX). http://ijellh. com/wp-content/uploads/2015/11/51.Dr.Kailash-Bhanudas-Yadav-paperfinal-1.pdf 